\title{
Frequency and coincidence of geriatric syndromes according to age groups: single-center experience in Turkey between 2013 and 2017
}

\author{
Esra Ates Bulut' \\ Pinar Soysal ${ }^{2}$ \\ Ahmet Turan Isik' \\ 'Department of Geriatric Medicine, \\ Faculty of Medicine, Dokuz Eylul \\ University, Izmir, Turkey; ${ }^{2}$ Department \\ of Geriatric Medicine, Faculty of \\ Medicine, Bezmialem Vakif University, \\ Istanbul, Turkey
}

This article was published in the following Dove Press journal: Clinical Interventions in Aging

Background: Geriatric syndromes are complex clinical manifestations that are not an isolated disease in older adults and have common risk factors within themselves. The syndromes are significant causes of mortality, morbidity, and increased health care costs.

Objective: To determine the frequency of geriatric syndromes such as malnutrition, dementia, depression, falls, polypharmacy, urinary incontinence, pressure ulcer, sarcopenia, and frailty in community-dwelling older adults.

Methods: A total of 2,816 patients, who applied to geriatric outpatient clinic and were evaluated by comprehensive geriatric assessment, were included in this cross-sectional retrospective study. Falls in the last year and urinary incontinence were recorded. Polypharmacy was accepted as concurrent use of more than four drugs. Diagnosis of dementia and depression was defined according to Diagnostic and Statistical Manual of Mental Disorders Fifth Edition diagnostic criteria. In addition, frailty and sarcopenia were evaluated according to Fried's physical frailty scale and European Working Group on Sarcopenia criteria, respectively.

Results: The frequency of polypharmacy was $54.5 \%$, urinary incontinence $47.6 \%$, malnutrition $9.6 \%$, depression $35.1 \%$, dementia $21.6 \%$, falls $33.6 \%$, sarcopenia $31.7 \%$, and frailty $28.3 \%$. When all the participants were divided into three groups $(60-69,70-79, \geq 80$ years), all syndromes were significantly increased with age, except for depression. While $20 \%$ of cases in 60-69 years age group did not have any syndromes, $48 \%$ of cases in $\geq 80$ years had more than four syndromes simultaneously.

Conclusion: The frequency and coincidence of geriatric syndromes, except for depression, increases with age. Therefore, clinicians other than geriatricians taking care of older people should be aware of these syndromes as well as their treatment mechanisms.

Keywords: geriatric syndromes, frailty, sarcopenia, dementia, malnutrition

\section{Introduction}

Geriatric syndromes are quite common clinical conditions in older adults that do not fall into specific disease categories. Different from the traditional definition of a "syndrome", they are further a symptom, or a fixed combination of several symptoms, and all the approaches for the management should consist of both search for a single or more diseases that precipitated the symptom(s) and of a multiple risk factor assessment; however, the pathogenesis, screening, and diagnostic tools of these heterogeneous situations have not been clearly defined. ${ }^{1}$ In addition, they are associated with increased morbidity, mortality, and health care utilization. In clinical practice, these conditions, such as cognitive impairment, falls, frailty, delirium, gait disturbances, incontinence, malnutrition, pain, polypharmacy, pressure ulcers, sarcopenia, sleep problems, and
Correspondence: Ahmet Turan Isik Yașlanan Beyin ve Demans Unitesi, Geriatri Bilim Dalı Dokuz Eylul

Universitesi, Tıp Fakultesi, 35340

Balcova - Izmir, Turkey

Tel +902324124341

Fax +902324124349

Email atisik@yahoo.com 
tremor, are named geriatric syndromes, and geriatricians play an important role in diagnoses and management of them. ${ }^{2,3}$ On the other hand, clinicians other than geriatricians taking care of older people, such as primary physicians, cardiologists, oncologists, and neurologists, should be aware of these syndromes.

Due to both development in the geriatric medicine and rapidly growing proportion of older people in the world, new geriatric syndromes have been defined, two of which are frailty and sarcopenia described in the last decade. While frailty is described as inadequate response to acute stressors due to decreased organ reserve and functions, ${ }^{4,5}$ sarcopenia is a geriatric syndrome that is associated with a decrease in muscle mass and function or strength. ${ }^{6}$ Frailty that has increased frequency with age is closely related to sarcopenia. Both syndromes have major adverse effects on activities of daily living and quality of life; furthermore, they increase hospitalization, morbidity, mortality, and risk of falls and fracture. ${ }^{7,8}$ Their pathogenesis has not been clearly elucidated and there is no diagnostic criteria that is universally accepted. Malnutrition, which is regarded as a separate syndrome, also presents as a risk factor for frailty and sarcopenia. ${ }^{9}$ Falls, one of the most important geriatric syndromes, cause severe disability and loss of functionality in the geriatric population. There are several risk factors for falls, such as polypharmacy, urinary incontinence, depression, and mobility disorders. Repeated falls contribute to the development of sarcopenia and frailty as they induce immobility and loss of muscle strength. ${ }^{10}$ Urinary incontinence has negative effects on quality of life, causing psychological problems in older adults. Urinary incontinence is one of the major reasons for referral to nursing homes, ${ }^{11}$ which increases caregiver burden, especially in patients with dementia as well as a risk factor for decubitus ulcers. ${ }^{12}$ Dementia has become a common diagnosis in aging populations, which is associated with a considerably increased risk of premature mortality, facilitating development of other geriatric syndromes such as malnutrition, delirium, incontinence, etc. ${ }^{13-16}$

Geriatric syndromes have common risk factors that are linked to each other within the cause and effect relationship. It is important to determine the changes that develop in the systems with aging, to predict which syndrome may develop in which patient, and to develop person-based protection and treatment options. The frequency of geriatric syndromes should be known according to age groups to enable the health care services to recognize the cases and refer patients to the necessary centers. ${ }^{17}$
The aim of this study was to show the frequency of malnutrition, dementia, depression, pressure ulcers, falls, polypharmacy, urinary incontinence, sarcopenia, and frailty according to age groups in community-dwelling older adults.

\section{Patients and methods}

The records of patients, who applied to the Dokuz Eylul University geriatric outpatient clinics between January 2013 and January 2017, were retrospectively reviewed. The study was designed as a retrospective cross-sectional study. The patients $\geq 60$ years of age, without exclusion criteria, were included in the study. The investigation was approved by the Dokuz Eylul University Ethics Committee for Non-Interventional Studies as a retrospective study. All participants provided written informed consent to use their medical records.

\section{Exclusion criteria}

1. Patients with severe osteoarthritis or neuromuscular disease, which causes obstacle to walking and immobile patients.

2. Patients who have a history of severe illness that may impair general health status, such as acute cerebrovascular event, gastrointestinal bleeding, sepsis, acute coronary syndrome, and acute respiratory failure.

3. Patients with alcohol and substance abuse.

4. Patients with malignancy (except patients who are in complete remission for at least 5 years).

5. Patients $<60$ years of age.

\section{Patients' characteristics}

Patients' information regarding age, gender, education level, accompanying systemic diseases, and number of drugs used was recorded. The patients were investigated for the presence of history of hypertension, coronary artery disease, diabetes mellitus, peripheral arterial disease, and cerebrovascular disease. The patients who used antihypertensive medication or had two separate blood pressure values $>140 / 90 \mathrm{mmHg}$ on appropriate measurement were accepted to have hypertension. Diabetes mellitus was defined as fasting plasma glucose levels $>126 \mathrm{mg} / \mathrm{dL}$ or HbAlc $>6.5 \%$. The patients were finally divided into three groups according to their age: 60-69 years, $70-79$ years, and $\geq 80$ years.

\section{Comprehensive geriatric assessment}

All the patients underwent comprehensive geriatric assessment, ${ }^{18}$ which included cognitive function, ${ }^{19}$ mood, ${ }^{20}$ activities of daily living, gait and balance functions, and nutritional evaluation. In an attempt to evaluate the global 
cognitive function, the Mini-Mental State Examination and the Montreal Cognitive Assessment scales were given to patients according to educational level. Geriatric Depression Scale was used to evaluate mood. Activities of daily living were assessed by Basic Activities of Daily Living Scale and Instrumental Activities of Daily Living scales. For nutritional status evaluation, the Mini Nutritional Assessment (MNA) test was carried out.

\section{Diagnosis of geriatric syndromes Dementia and depression}

These syndromes were diagnosed according to Diagnostic and Statistical Manual of Mental Disorders, Fifth Edition $(D S M-V)$ criteria.

\section{Falls}

It was accepted positive if the patient had fallen in the previous year except for tripping on a rug and slipping on wet floor.

\section{Frailty}

A modified Fried physical frailty scale was used to evaluate the frailty, which was defined according to physical model and the presence of three or more of the following criteria: weight loss, exhaustion, low physical activity, slowness, and weakness. ${ }^{4}$ Low physical activity was considered positive in patients who spend majority of their time sitting or rarely have short walks in the past year, instead of using Minnesota Leisure Time Questionnaire. ${ }^{21}$

\section{Malnutrition}

The European Society of Clinical Nutrition and Metabolism recommends MNA as a screening tool for malnutrition in older adults. ${ }^{22}$ Patients with MNA short-form score $\leq 7$ points are considered as having malnutrition.

\section{Polypharmacy}

It is stated as concomitant five or more drug usage. ${ }^{18}$

\section{Pressure ulcers}

This is defined as localized damage to the skin and/or underlying tissue that usually occurs over a bony prominence as a result of pressure, or pressure in combination with shear and/ or friction that generally occurs in immobile patients.

\section{Sarcopenia}

For the evaluation of walking speed, muscle strength, and muscle mass in patients, Four-Meter Walking Test, handgrip test, and bioimpedance were performed for each patient, respectively. Handgrip test was measured by Jamar hydrolic hand dynamometer (Model J00105; Lafayette Instruments, Lafayette, IN, USA), and bioimpedance was established by Tanita (MC-780U; Multi Frequency Segmental Body Composition, Tokyo, Japan). We accepted slow walking speed as $<0.8 \mathrm{~m} / \mathrm{sec}$, and weakness, assessed by grip strength of the dominant hand with dynamometer, was accepted to be less than $20 \mathrm{~kg}$ in females and $30 \mathrm{~kg}$ in males. ${ }^{4}$ Based on muscle mass bioimpedance values, skeletal muscle $(\mathrm{kg})=$ $\left(\right.$ height $\left.^{2} / R \times 0.401\right)+(\operatorname{sex} \times 3.825)+($ age $\times-0.071)+5.102$ is formulated. ${ }^{23}$ Values in terms of resistance $(R) 50 \mathrm{~Hz}$ hand-leg (body), length in centimeters, female gender 0 , male gender 1 , and age in years are accepted and replaced in formula. The skeletal muscle mass index (SMI = muscle mass $/$ height $^{2}$ ) was calculated by dividing the muscle mass in $\mathrm{kg}$ by length in square meters, which was obtained to prevent the muscle mass from varying according to the height. SMI was regarded as low when muscle mass was $<8.87 \mathrm{~kg} / \mathrm{m}^{2}$ for males and $<6.42 \mathrm{~kg} / \mathrm{m}^{2}$ for females. ${ }^{6}$ Decreased muscular strength and/or walking speed together with decreased muscle mass were evaluated as sarcopenia. ${ }^{6}$

\section{Urinary incontinence}

It was considered to be present in cases having involuntary urinary leakage in the last 3 months except for urinary tract infection. ${ }^{24}$

\section{Statistical analysis}

Analysis of the data was done in SPSS for Windows 22 package program (SPSS Inc., Chicago, IL, USA). Descriptive statistics are shown as mean $\pm \mathrm{SD}$ for variables with normal distribution, median (minimum to maximum) for non-normal distributions, and the number of cases and percentage (\%) for nominal variables. When the number of groups involved was two, the significance of differences between the groups in terms of averages was investigated by Student's $t$-test and in terms of median values was investigated by Mann-Whitney test. When the number of groups was more than two, the significance of differences between the groups in terms of averages was investigated by the ANOVA variance analysis test and the significance of medians was determined by the Kruskal-Wallis test. Nominal variables were assessed by Pearson's chi-squared or Fisher's exact test. Results for $P<0.05$ were considered statistically significant. Although the total number of patients included in this study was 2,816 , there were 1,017 patients who had bioimpedance analysis. Therefore, estimated frailty and sarcopenia rates are calculated with an acceptable error of 5\% and a 95\% CI in all age groups separately. 


\section{Results}

A total of 2,816 patients were included in the study. Median age of patients was 76 years, minimum age was 60 years, and maximum age was 105 years. The average age of females and males was $75.42 \pm 8.34$ and $75.88 \pm 8.12$ years, respectively. Among them, $65 \%$ of the patients were female. The demographic characteristics of the patients are shown in Table 1.

The patients were divided into three groups according to age: $60-69,70-79$, and $\geq 80$ years. A total of 728,1137 , and 951 patients were included in the groups, respectively. Urinary incontinence, falls, depression, dementia, polypharmacy, malnutrition, sarcopenia, frailty, and pressure ulcers were evaluated. Prevalence was $54.5 \%$ for polypharmacy, $47.6 \%$ for urinary incontinence, $9.6 \%$ for malnutrition, $35.1 \%$ for depression, $21.6 \%$ for dementia, $33.6 \%$ for falls, $31.7 \%$ for sarcopenia, $28.3 \%$ for frailty, and $1.1 \%$ for pressure ulcers. All geriatric syndromes, except for depression and pressure ulcers, were found to be significantly more common with advancing age. When we analyzed geriatric syndromes according to both sex and age groups, while depression and frailty were frequent in females, dementia was frequent in males in all age groups. Figure 1 shows the frequency of geriatric syndrome according to age groups.

Frailty and sarcopenia status were evaluated in 1,017 patients whose bioimpedance, muscle strength, walking speed data were complete. Of them, 218 were frail and 313 were sarcopenic, and $53 \%$ of the patients who were frail were also sarcopenic. We calculated the estimated frequency of frailty in 60-69 years group $(6 \%-11 \%), 70-79$ years (26\%-35\%), $\geq 80$ years (41\%-54\%); sarcopenia in 60-69years group $(7 \%-14 \%), 70-79$ years $(26 \%-35 \%)$, $\geq 80$ years
$(50 \%-63 \%)$ with an acceptable error of $5 \%$ and a $95 \%$ confidence level.

While the rate of having four or more syndromes in the same person was $27.1 \%, 12 \%$ had no geriatric syndrome, $22.9 \%$ had one syndrome, and $21 \%$ had two syndromes. In particular, the frequency of having three or more syndromes in the same age group at $\geq 80$ years was calculated as $68.8 \%$. Figure 2 shows the coincidence of syndromes according to age groups.

\section{Discussion}

Geriatric medicine has some dissimilarities from the usual Hippocratic medicine. Individual targets are important to achieve instead of reference intervals in older adults. Geriatric syndromes are also different from the usual syndromes that have many common etiological factors or diseases, and geriatric patients usually suffer from more than one geriatric syndrome simultaneously. ${ }^{25}$ This study shows the frequency of nine different geriatric syndromes at the same time according to age groups. It was seen that the frequency of all syndromes and coincidence increased with aging except for pressure ulcers and depression.

The prevalence of frailty and sarcopenia in this study was found to be consistent with community-dwelling older adults in the literature. The rates of sarcopenia and frailty were reported to be $24 \%{ }^{7}$ and $26 \%{ }^{8}$ in other studies from Turkey. The prevalence of frailty varies by $30 \%-40 \%$ and the frequency increases with age and ethnical differences may be seen. ${ }^{4,26}$ Also, their frequent coincidence suggests the common pathogenetic mechanisms in the etiology. Even in the literature, these two syndromes were described as "two sides of the same coin". ${ }^{27}$ There are many changes with aging such

Table I Demographic characteristics of patients

\begin{tabular}{|c|c|c|c|c|}
\hline Patients' characteristics & $\begin{array}{l}60-69 \text { years } \\
N=728\end{array}$ & $\begin{array}{l}\text { 70-79 years } \\
N=1,137\end{array}$ & $\begin{array}{l}\geq 80 \text { years } \\
N=951\end{array}$ & $P$-value \\
\hline Sex (female \%) & 68 & 64 & 65 & 0.22 \\
\hline Marital status (married \%) & 73 & 59 & 38 & $<0.01$ \\
\hline Education > II years $(\%)$ & 48 & 34 & 30 & $<0.01$ \\
\hline \multicolumn{5}{|l|}{ Comorbid diseases (\%) } \\
\hline Diabetes mellitus & 25 & 30 & 26 & $<0.01$ \\
\hline Hypertension & 54 & 69 & 73 & $<0.01$ \\
\hline Cerebrovascular disease & 5 & 8 & 11 & $<0.01$ \\
\hline Coronary artery disease & 12 & 18 & 22 & $<0.01$ \\
\hline Peripheral arterial disease & 3 & 5 & 5 & 0.05 \\
\hline Congestive heart failure & 3 & 7 & 12 & $<0.01$ \\
\hline Chronic Obstructive Pulmonary Disease & 8 & 10 & 10 & 0.23 \\
\hline Charlson comorbidity index & $0.7 I \pm 0.94$ & $1.11 \pm 1.21$ & $1.34 \pm 1.25$ & $<0.01$ \\
\hline
\end{tabular}

Note: Bold text indicates $p<0.05$. 


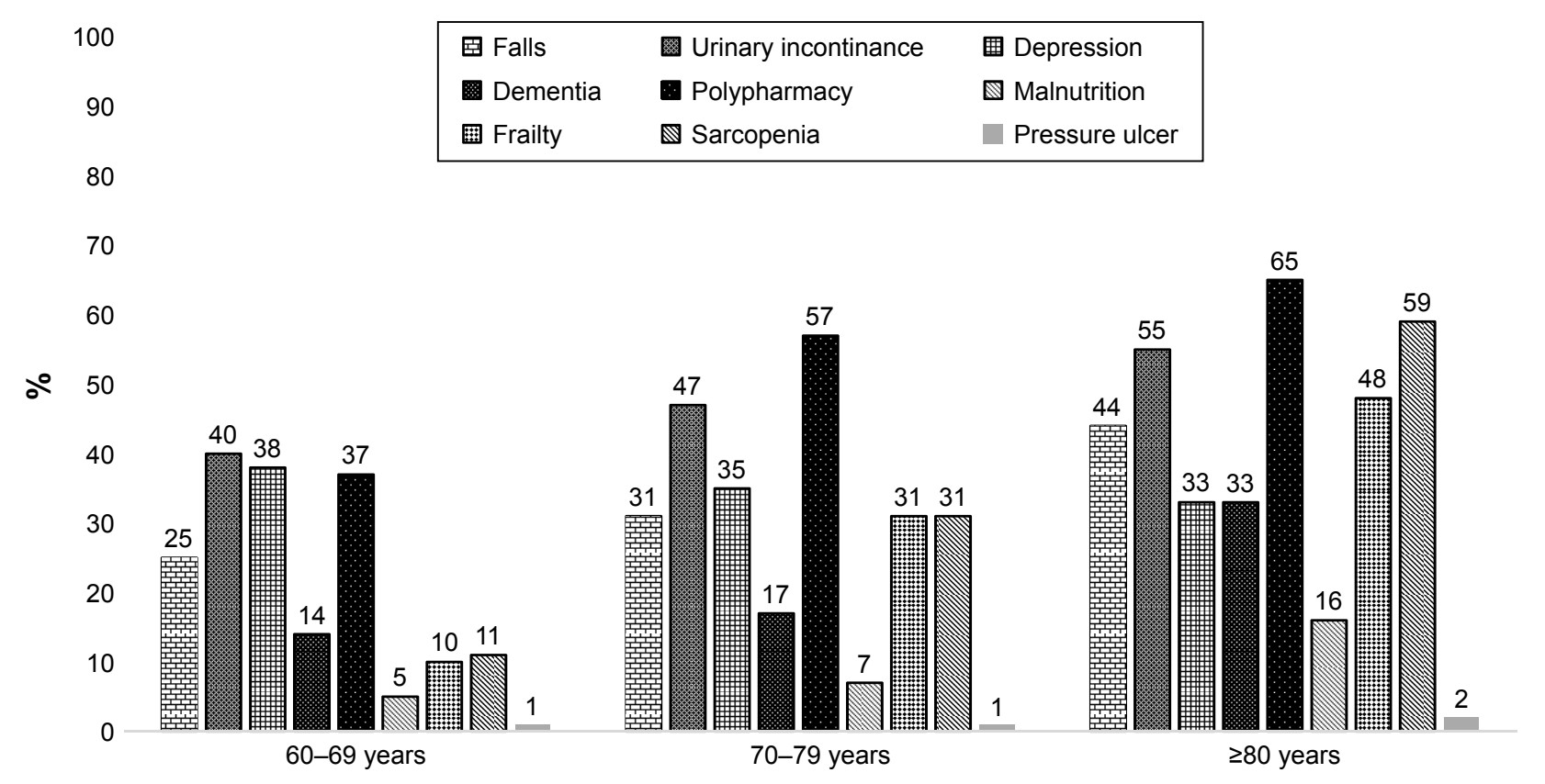

Figure I Frequency of geriatric syndromes according to age groups (\%).

as decreasing muscle mass in body composition, neuronal plasticity, cellular regeneration capacity, and response to stressors. The resultant vulnerable state may give rise to decompensation and unhealthy state. ${ }^{28}$ Accordingly, the studies also showed that frailty and sarcopenia are closely related to falls, cognitive impairment, polypharmacy, and malnutrition, and are thought to result in a vicious cycle in the cause-and-effect relationship with common pathogenetic mechanisms. ${ }^{29}$

The prevalence of polypharmacy, dementia, and urinary incontinence was seen to be consistent with that reported in the literature. ${ }^{30-33}$ In the studies mentioned earlier, it is stated that the syndromes are seen more frequently with increasing age. The risk of malnutrition and malnutrition rates assessed

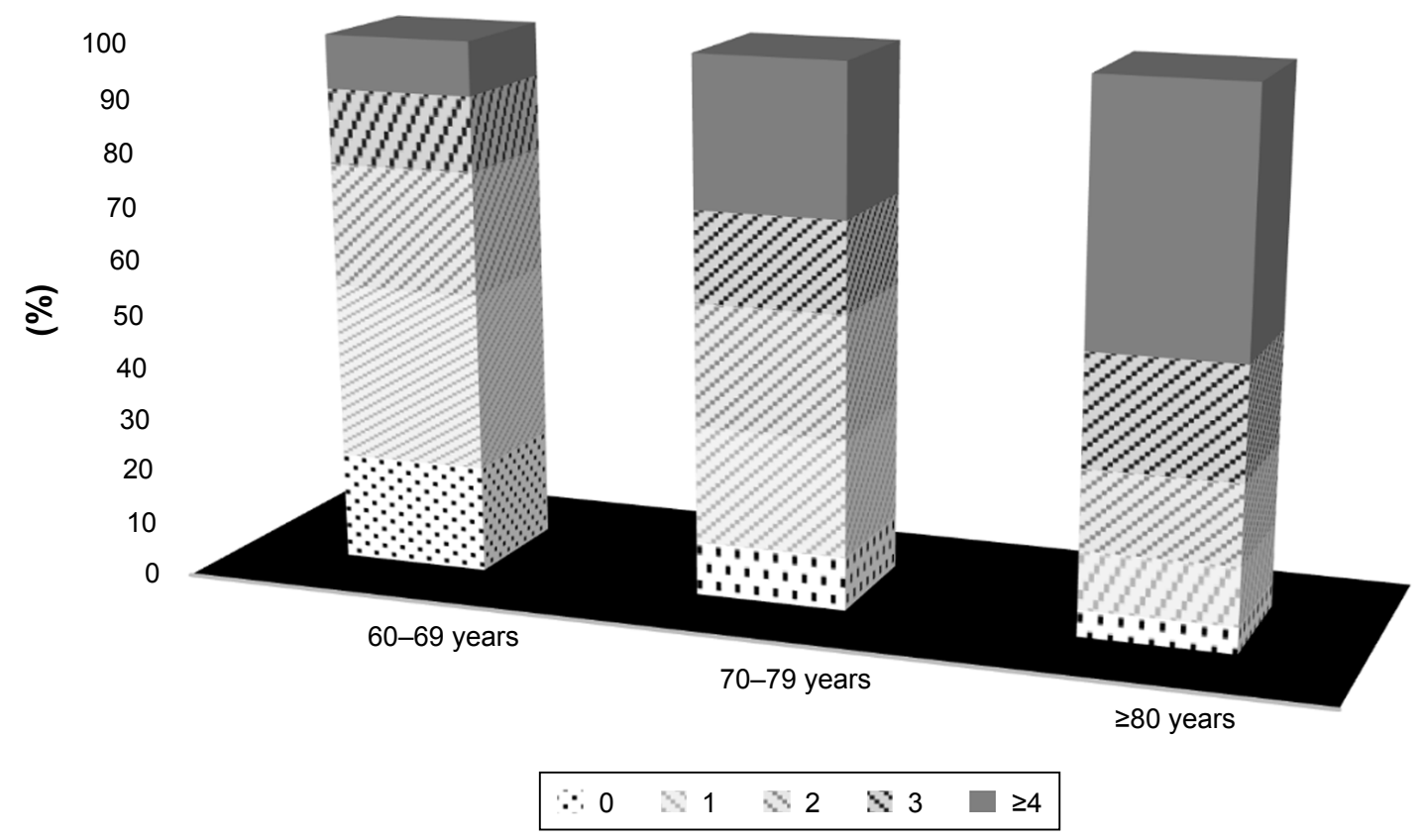

Figure 2 Total number of geriatric syndromes according to age groups (\%).

Note: Bar chart shows total number of geriatric syndromes one on the top of the other in each age group as percentage. 
by MNA in another study was pointed to be $15 \%$ and $40 \%$, respectively. Malnutrition rate was reported to be $13 \%$ in a Turkish study. ${ }^{34}$ The malnutrition rate in our study was similar with the literature. ${ }^{35}$ The prevalence of pressure ulcers was reported to be $4.5 \%-18 \%$ in hospitalized and nursing homes. ${ }^{36,37}$ It is estimated that our frequency is lower due to the exclusion of hospitalized acute care patients.

Geriatric depression is a frequent syndrome associated with increased disability, mortality, and worsening of medical illness in patients. Progressive age, female gender, loss of spouse, changes in social and business life, low income, educational level, and increased comorbidity are associated with depressive mood..$^{38}$ Prevalence is indicated to be between $7 \%$ and $49 \%$ in the literature. ${ }^{39}$ In this study, prevalence was $36 \%$ and no relation was observed with increasing age, which may be explained by Blazer and Jorm's suggestions that frequency of depression reduces with age because of a multitude of factors, such as decreased emotional responsiveness, increased emotional control, and psychological immunization. ${ }^{40,41}$

Many cumulative molecular and biochemical changes take place from cells to organ systems with aging process. As a result, the regeneration reserve of organs and functional capacity decline. Patients are susceptible to increased comorbidity, polypharmacy, nutritional deficiencies, visual and auditory disorders, decreased muscle mass, balance problems, and cognitive impairment. ${ }^{42}$ Multimorbidity and related comorbidity indexes help to predict health care admission, mortality, and physical function. In this study, it is also shown that comorbid diseases' frequency as well as comorbidity index score increase with aging. ${ }^{43}$ Detection and treatment of these situations in the early period prevent adverse outcomes in older adults. As seen in the study, at least four syndromes are seen in one of two patients aged $\geq 80$ years. Multiple comorbidities are difficult to manage in these patients, and patients are predisposed to geriatric syndromes and atypical presentations.

The strengths of this study are large sample size and a detailed examination of geriatric syndromes. Previous prevalence studies have generally examined only three or four syndromes at the same time. When we look at the limitations, only outpatients were included in the study and cross-sectional data were used. The delirium frequency could not be checked due to exclusion of the acute care patients in the hospital and there were not enough samples for the pressure ulcers; thus, the frequency of these two important syndromes could not be obtained.

\section{Conclusion}

In brief, we aimed to show the frequency of geriatric syndromes in the older adults in community according to age groups. Together with the aging population, we would like to emphasize that these patients and associated syndromes are of interest not only for geriatricians but should also be recognized at all levels of health centers and by all of the clinicians who have to evaluate and treat older patients. Therefore, all educational programs related to older adults should include these main topics. Geriatric syndromes cause serious mortality and morbidity and increase health care costs. Identification of the underlying etiopathogenesis, accurate diagnosis, and appropriate treatment guidelines are necessary, and integrated health systems should be established for the prevention and treatment of these syndromes.

\section{Acknowledgments}

The authors thank Idil Yavuz for statistical analysis. This research did not receive any specific grant from funding agencies of the public, commercial, or not-for-profit sectors.

\section{Disclosure}

The authors report no conflicts of interest in this work.

\section{References}

1. Olde Rikkert MG. Conceptualizing geriatric syndromes. In: Jean-Pierre M, Lynn Beattie B, Martin Finbarr C, Walston JD, editors. Oxford Textbook of Geriatric Medicine. 3rd ed. Oxford: Oxford University Press; 2017.

2. Inouye SK, Studenski S, Tinetti ME, Kuchel GA. Geriatric syndromes: clinical, research, and policy implications of a core geriatric concept. J Am Geriatr Soc. 2007;55(5):780-791.

3. Saraf AA, Petersen AW, Simmons SF, et al. Medications associated with geriatric syndromes and their prevalence in older hospitalized adults discharged to skilled nursing facilities. J Hosp Med. 2016; 11(10):694-700.

4. Fried LP, Tangen CM, Walston J, et al. Frailty in older adults: evidence for a phenotype. J Gerontol A Biol Sci Med Sci. 2001;56(3):M146-M156.

5. Soysal P, Stubbs B, Lucato P, et al. Inflammation and frailty in the elderly: A systematic review and meta-analysis. Ageing Res Rev. 2016; 31:1-8.

6. Cruz-Jentoft AJ, Baeyens JP, Bauer JM, et al. Sarcopenia: European consensus on definition and diagnosis: Report of the European Working Group on Sarcopenia in Older People. Age Ageing. 2010;39(4):412-423.

7. Bulut EA, Soysal P, Aydin AE, Dokuzlar O, Kocyigit SE, Isik AT. Vitamin B12 deficiency might be related to sarcopenia in older adults. Exp Gerontol. 2017;95:136-140.

8. Dokuzlar O, Soysal P, Isik AT. Association between serum vitamin B12 level and frailty in older adults. North Clin Istanb. 2017;4(1):22-28.

9. Cruz-Jentoft AJ, Kiesswetter E, Drey M, Sieber CC. Nutrition, frailty, and sarcopenia. Aging Clin Exp Res. 2017;29(1):43-48.

10. Swift CG. The role of medical assessment and intervention in the prevention of falls. Age Ageing. 2006;35(Suppl 2):ii65-ii68.

11. Vaughan CP, Goode PS, Burgio KL, Markland AD. Urinary incontinence in older adults. Mt Sinai J Med. 2011;78(4):558-570. 
12. Ayello EA, Lyder CH. Protecting patients from harm: preventing pressure ulcers in hospital patients. Nursing. 2007;37(10):36-40.

13. Isik AT. Delirium Superimposed on Dementia. Isik AT, Grossberg GT, editors. Delirium in Elderly Patients. Cham, Switzerland: Springer International Publishing; 2018:39-48.

14. Isik AT. Late onset Alzheimer disease in older people. Clin Interv Aging. 2010;5:307-311.

15. Soysal P, Isik AT, Stubbs B, et al. Acetylcholinesterase inhibitors are associated with weight loss in older people with dementia: a systematic review and meta-analysis. J Neurol Neurosurg Psychiatry. 2016; 87(12):1368-1374.

16. Isik AT, Celik T, Bozoglu E, Doruk H. Trospium and cognition in patients with late onset Alzheimer disease. $J$ Nutr Health Aging. 2009;13(8):672-676.

17. Senn N, Monod S. Development of a Comprehensive Approach for the Early Diagnosis of Geriatric Syndromes in General Practice. Front Med (Lausanne). 2015;2:78.

18. Unutmaz GD, Soysal P, Tuven B, Isik AT. Costs of medication in older patients: before and after comprehensive geriatric assessment. Clin Interv Aging. 2018;13:607-613.

19. Babacan-Yildiz G, Isik AT, Ur E, et al. COST: Cognitive State Test, a brief screening battery for Alzheimer disease in illiterate and literate patients. Int Psychogeriatr. 2013;25(3):403-412.

20. Durmaz B, Soysal P, Ellidokuz H, Isik AT. Validity and Reliability of Geriatric Depression Scale - 15 (Short Form) in Turkish older adults. North Clin Istanb. 2017.

21. Cesari M, Leeuwenburgh C, Lauretani F, et al. Frailty syndrome and skeletal muscle: results from the Invecchiare in Chianti study. Am J Clin Nutr. 2006;83(5):1142-1148.

22. Cederholm T, Barazzoni R, Austin P, et al. ESPEN guidelines on definitions and terminology of clinical nutrition. Clin Nutr. 2017; 36(1):49-64.

23. Janssen I, Heymsfield SB, Baumgartner RN, Ross R. Estimation of skeletal muscle mass by bioelectrical impedance analysis. $J$ Appl Physiol. 2000;89(2):465-471.

24. Parazzini F, Cipriani S, de'Besi P, Lavezzari M, Artibani W; Gruppo Interdisciplinare di Studio Incontinenza Urinaria. Urinary incontinence: frequency and diagnostic and therapeutic approach in general practice in Italy. Arch Ital Urol Androl. 2001;73(3):160-167. Italian.

25. Olde Rikkert MG, Rigaud AS, van Hoeyweghen RJ, de Graaf J. Geriatric syndromes: medical misnomer or progress in geriatrics? Neth $J$ Med. 2003;61(3):83-87.

26. Collard RM, Boter H, Schoevers RA, Oude Voshaar RC. Prevalence of frailty in community-dwelling older persons: a systematic review. $J$ Am Geriatr Soc. 2012;60(8):1487-1492.

27. Cesari M, Landi F, Vellas B, Bernabei R, Marzetti E. Sarcopenia and physical frailty: two sides of the same coin. Front Aging Neurosci. 2014;6:192.
28. Bektas A, Schurman SH, Sen R, Ferrucci L, Aging FL. Aging, inflammation and the environment. Exp Gerontol. 2018;105:10-18.

29. Bennett A, Gnjidic D, Gillett M, et al. Prevalence and impact of fallrisk-increasing drugs, polypharmacy, and drug-drug interactions in robust versus frail hospitalised falls patients: a prospective cohort study. Drugs Aging. 2014;31(3):225-232.

30. Safran DG, Neuman P, Schoen C, et al. Prescription drug coverage and seniors: findings from a 2003 national survey. Health Affairs (Project Hope). 2005; Suppl Web Exclusives:W5-152-w5-66.

31. Plassman BL, Langa KM, Fisher GG, et al. Prevalence of dementia in the United States: the aging, demographics, and memory study. Neuroepidemiology. 2007;29(1-2):125-132.

32. Roberts RO, Jacobsen SJ, Rhodes T, et al. Urinary incontinence in a community-based cohort: prevalence and healthcare-seeking. $J \mathrm{Am}$ Geriatr Soc. 1998;46(4):467-472.

33. Munch T, Harrison SL, Barrett-Connor E, et al. Pain and falls and fractures in community-dwelling older men. Age Ageing. 2015;44(6): 973-979.

34. Saka B, Kaya O, Ozturk GB, Erten N, Karan MA. Malnutrition in the elderly and its relationship with other geriatric syndromes. Clin Nutr. 2010;29(6):745-748.

35. Win AZ, Ceresa C, Arnold K, Allison TA. High Prevalence of Malnutrition among Elderly Veterans in Home Based Primary Care. J Nutr Health Aging. 2017;21(6):610-613.

36. Bredesen IM, Bjøro K, Gunningberg L, Hofoss D. The prevalence, prevention and multilevel variance of pressure ulcers in Norwegian hospitals: a cross-sectional study. Int J Nurs Stud. 2015;52(1): 149-156.

37. Gunningberg L, Hommel A, Bååth C, Idvall E. The first national pressure ulcer prevalence survey in county council and municipality settings in Sweden. J Eval Clin Pract. 2013;19(5):862-867.

38. Blazer DG. Depression in late life: review and commentary. J Gerontol A Biol Sci Med Sci. 2003;58(3):249-265.

39. Djernes JK. Prevalence and predictors of depression in populations of elderly: a review. Acta Psychiatr Scand. 2006;113(5):372-387.

40. Blazer DG. Protection from late life depression. Int Psychogeriatr. 2010;22(2):171-173.

41. Jorm AF. Does old age reduce the risk of anxiety and depression? A review of epidemiological studies across the adult life span. Psychol Med. 2000;30(1):11-22.

42. Bolt K, Bergman A. Systems biology of aging. Adv Exp Med Biol. 2015;847:163-178.

43. Wei MY, Mukamal KJ. Multimorbidity, Mortality, and Long-Term Physical Functioning in 3 Prospective Cohorts of CommunityDwelling Adults. Am J Epidemiol. 2018;187(1):103-112.
Clinical Interventions in Aging

\section{Publish your work in this journal}

Clinical Interventions in Aging is an international, peer-reviewed journal focusing on evidence-based reports on the value or lack thereof of treatments intended to prevent or delay the onset of maladaptive correlates of aging in human beings. This journal is indexed on PubMed Central, MedLine,

\section{Dovepress}

CAS, Scopus and the Elsevier Bibliographic databases. The manuscript management system is completely online and includes a very quick and fair peer-review system, which is all easy to use. Visit http://www.dovepress. com/testimonials.php to read real quotes from published authors. 